\title{
BEST PRACTICES FOR \\ DEFENCE ACQUISITION REFORM IN SOUTH AFRICA
}

\author{
A J Swart and A J Buys \\ Institute for Technological Innovation \\ University of Pretoria \\ ajbuys@up.ac.za
}

\begin{abstract}
This paper investigates the best practices and acquisition reform initiatives in the US Department of Defence that are relevant for the defence acquisition reform process in South Africa. The first part of the paper gives a short discussion on acquisition methods commonly used by defence departments, briefly defines what acquisition reform is and states the applicable principles that can be used for acquisition reform. The second part gives the advantages and disadvantages of some of the acquisition reform initiatives and best practices that were identified. The relevance of each of these initiatives and best practices to the South African acquisition reform effort is indicated. The last part describes an acquisition reform model that can be used as a basis to make acquisition better, faster and cheaper. Finally, some recommendations are made on the way forward and actions to be taken that will help to speed up the acquisition reform effort in South Africa.
\end{abstract}

\section{OPSOMMING}

In hierdie artikel word die beste praktyke en aanskaffinghervorming inisiatiewe van die VSA Departement van Verdediging, wat relevant is vir die hervorming van verdedingingaanskaffing in Suid-Afrika, ondersoek. Die eerste deel van die artikel bevat ' $n$ kort bespreking van aanskaffingmetodes wat algemeen deur verdedigingsdepartemente gebruik word. Aanskaffinghervorming word kortliks gedefineer en die toepaslike beginsels wat gebruik kan word vir aanskaffinghervorming word uiteengesit. Die tweede deel gee die voor- en nadele van sommige aanskaffinghervorming inisiatiewe en beste praktyke wat geidentifiseer is. Die relevansie van elk van hierdie inisiatiewe en beste praktyke vir aanskaffingherforming in Suid-Afrika word aangedui. Die laaste deel beskryf "n aanskaffinghervormingsmodel wat gebruik kan word as basis om aanskaffing beter, vinniger en goedkoper te maak. Ter slotte word ' $n$ aantal aanbevelings gemaak oor die pad vorentoe en aksies wat geneem kan word om aanskaffinghervorming in Suid-Afrika te bespoedig. 


\section{ACRONYMS USED IN THIS ARTICLE}

$\begin{array}{ll}\text { AR } & \text { Acquisition Reform } \\ \text { ASRP } & \text { Acquisition and Sustainment Reinvention Process } \\ \text { CAIV } & \text { Cost as an Independent Variable } \\ \text { CALS } & \text { Continuous Acquisition and Life-Cycle Support } \\ \text { CDRL } & \text { Contract Data Requirements List } \\ \text { COTS } & \text { Commercial off the Shelf } \\ \text { DoD } & \text { Department of Defence } \\ \text { EA } & \text { Evolutionary Acquisition } \\ \text { EDI } & \text { Electronic Data Interchange } \\ \text { ESS } & \text { Electronic Source Selection } \\ \text { EVMS } & \text { Earned Value Management Systems } \\ \text { IDE } & \text { Integrated Data Environment } \\ \text { ILS } & \text { Integrated Logistic Support } \\ \text { IPPD } & \text { Integrated Product and Process Development } \\ \text { IPT } & \text { Integrated Product Teams } \\ \text { LCC } & \text { Life Cycle Cost } \\ \text { NDI } & \text { Non-Developmental Items } \\ \text { O\&S } & \text { Operating and Support } \\ \text { OIPT } & \text { Overarching Integrated Product Teams } \\ \text { OS } & \text { Open System } \\ \text { PPI } & \text { Past Performance Information } \\ \text { RFP } & \text { Request for Proposal } \\ \text { R-TOC } & \text { Reduction of Total Ownership Cost } \\ \text { SA } & \text { South Africa } \\ \text { SANDF } & \text { South African National Defence Force } \\ \text { SAP } & \text { Simplified Acquisition Procedures } \\ \text { SOW } & \text { Statement of Work } \\ \text { SPI } & \text { Single Process Initiative } \\ \text { TOC } & \text { Total Ownership Cost } \\ \text { URS } & \text { User Requirements Specifications } \\ \text { US } & \text { United States } \\ \text { WBS } & \text { Work Breakdown Structure } \\ & \end{array}$




\section{BACKGROUND}

The South African White Paper on Defence [1], as approved by Parliament in May 1996, states that the South African National Defence Force (SANDF) shall be a balanced, modem, affordable and technologically advanced military force, capable of executing its tasks effectively and efficiently. This requires the development, maintaining, upgrading and replacement of weapons and equipment in the SANDF in the most cost-effective way. For the SANDF to carry out its primary role, the availability of armaments is essential. Optimal modern armaments for the SANDF are obtained through a process of armament acquisition.

The Armscor and South African Department of Defence (DoD) acquisition process is similar to the former United States (US) DoD process as contained in US DoD 5000-series directives [2]. The US DoD 5000 series has, however, changed dramatically in the last few years. Aggressive efforts from the US DoD addressing specific areas of Acquisition Reform (AR) have already saved or resulted in cost avoidance of over $\$ 60$ billion in recent years. Changes in the external environment of the SANDF are similar to the US situation and probably more emphasised. Armscor investigation into the cost/time associated with the current acquisition process indicated that the current process is too costly, too long and too rigid.

The key players that will interact in defence AR in South Africa (SA) include the SANDF, the Defence Secretariat and Armscor. These three role players are considered to be in a partnership and decision making at all levels allows for the viewpoints of the three partners.

\section{INTRODUCTION}

For years, the competition for scarce resources such as funding, personnel, and time, increased and it will continue to be intense in the years to come. There are more systems desired than affordable, a premium on skilled personnel, an increasingly dynamic business environment, and increased sensitivity to the efficiency and effectiveness of our use of resources. Not only were numerous acquisition problem areas identified, but also opportunities for improving the way to manage limited resources.

One of the biggest dilemmas that the SANDF is facing right now is a very tight budget. There are large demands for very limited resources. Everything that is required is simply not affordable. Widespread implementation of AR is a necessary action in the SA Defence environment, so that the required defence capabilities can be delivered better, cheaper and faster.

Using past successes as a foundation, the ways to accomplish acquisition and support of systems across their entire life cycles must be reshaped. Only by critically re-examining the core processes that are used for acquisition and support activities - that is, taking a processoriented approach - can non-essential/non-value-adding activities be eliminated. According to the US Deputy Under Secretary of Defense for Acquisition Reform [3] this AR culture will leave only one option: "To control our destiny and our spending now, or risk having someone else do it for us".

This report discusses certain US Defence AR initiatives and practices that may be relevant and useful for AR in SA. It is however important to keep in mind that it is not possible for SA. 
to implement all the US Defence AR initiatives and practices due to the major differences in the acquisition workforces and environments.

\section{WHAT IS ACQUISITION REFORM?}

According to the US Deputy Under Secretary of Defense for Acquisition Reform [3], AR is a program to achieve the military acquisition objectives at a reduced cost and with increased responsiveness to customers. AR is therefore not only to streamline acquisition processes or to upgrade acquisition policies, but also to look at all the necessary resources, actions, organisations and infrastructure needed to provide and support products and services for the customer. The emphasis should be on best value and affordability as opposed to lowest price. The aim of AR is to have successful acquisition programs that place capable and supportable systems in the hands of the user, when and where it is needed, and within the bounds of affordability.

AR in SA should start with a culture change within the acquisition workforce. The SANDF, Armscor and the Defence Secretariat should work together towards more co-operative and coordinated acquisition efforts. AR projects should be identified and driven by AR champions. This entails the total spectrum of activities to be carried out by the participating organisations within the defence family to meet the armament requirements better, cheaper and faster to ensure that the SANDF has the necessary user systems for maintaining a combat-ready capability.

\section{ACQUISITION REFORM PRINCIPLES}

The following AR principles were identified and used as a basis during the research to identify applicable best practices to be used in SA defence acquisition:

- Reduce cost of ownership.

- Use performance-based requirements.

- Use Integrated Product and Process Development (IPPD) and Integrated Product Teams (IPT).

- Manage risk.

- Encourage innovation.

- Streamline.

- Use commercial practices, products and processes.

- Use on-line electronic media.

- Use unobtrusive testing techniques.

- Use best value techniques.

\section{ACQUISITION METHODS}

Acquisition is a method of acquiring systems, which includes conceptualisation, design, development, test, contracting, production, deployment, logistic support, modification and disposal of systems, products, supplies or services. Traditional approaches include grand design, incremental acquisition and phased acquisition. 


\section{Grand Design Acquisition}

The grand design approach requires all requirements to be specified at the start of the project and assumes that the system, as specified, will be delivered at the end of the process. There is a strong emphasis on planning the project (or phase) in advance. It is essentially a "oncethrough, do-each-step-once" strategy, i.e. determine user needs, define requirements, design the system, and implement the system, test, fix, and deliver.

\section{Incremental Acquisition}

According to the US Office of the Secretary of Defense [4], incremental acquisition involves building a system in a series of increments, each adding to the capability of the previous one. There is usually a single contract and all requirements are assumed to be known at the beginning of the project.

\section{Phased Acquisition}

In phased acquisition the acquisition is divided into phases, allowing decision points (and often delays) between phases, when the direction of a project may be significantly changed. The actual acquisition model for each phase is not specified, and might be, for example, grand design or incremental acquisition. Phased acquisition is the official method used by Armscor [5]. There are currently six different phases defined in the system hierarchy integration process for SA defence acquisition.

Although Armscor's general policy for the management of the acquisition process is only used as a guideline for acquisition, it became more and more difficult to use one general method or model for all types of projects, especially complex programs. To determine the effectiveness of different acquisition methods for different types of acquisition projects is one area on which AR can focus.

\section{Evolutionary Acquisition}

Traditional acquisition strategies often fail (or are unable) to take rapid technological change into account and advances in technology are not easily incorporated into systems when the advances occur during the project development cycle. Consequently, many of the resultant systems do not meet the users' expectations, cost too much and take too long to develop (due to the strategy's weakness in accommodating changes), and are expensive to maintain.

According to the US Under Secretary of Defense's "Defence Acquisition Deskbook" [6], Evolutionary Acquisition (EA) is an alternative approach with the potential to produce significantly better results. EA has, however, not been widely used due to the concern that EA is inherently risky. However, for certain types of projects, risks may be significantly greater in traditional strategies, than those in EA strategies.

The main thrust of EA is the specification, design, implementation, testing, delivery, operation and maintenance of systems (not prototypes) incrementally. Delivery of each incremental release increases the capability of the system until complete. Users have early access to system releases and are encouraged to provide feedback on performance. This will 
then shape the system as it evolves into its final form.

Projects that are suited to EA will normally have some or all of the following characteristics:

- Software intensive systems.

- Systems using rapidly changing technology.

- Systems where humans are an integral part of the system.

- Systems with a large number of diverse users.

- When the system is unprecedented.

- A limit capability is needed quickly.

These systems usually have requirements that are difficult to capture and define and which are likely to change during the life of the project. EA projects are also likely to utilise commercial technology that is emergent or quickly changing, making it particularly suitable for information technology projects.

When used correctly for appropriate projects, EA can provide significant benefits over traditional acquisition models. The benefits include:

- Better requirements earlier in the acquisition process.

- More feasible requirements.

- Fielding an early operational capability.

- Incorporation of new technology.

- More control and visibility of project progress.

- Better systems that more closely meet their users' needs when delivered.

- Lower support costs because the need for early modifications is reduced.

Some of the penalties, which will normally be incurred in using EA, as compared with a grand design approach, are:

- Additional and duplicated activities and interaction required.

- Frequent changes in direction, which may result in nugatory work being done and delays to the schedule.

- Greater projected cost and schedule.

- Better and more management necded.

- Impact of concurrent activities.

- Better configuration management needed.

- Technical support for the acquirer.

- User resources and co-ordination.

- Support for fielded releases.

EA is a highly dynamic and flexible approach to the acquisition of complex systems. As such, it involves higher levels of risks in a number of areas that need to be controlled if the project is to be successful.

It is clear that EA is therefore not an easy or simplified option for acquisition. It is however believed that that there are real benefits to be gained from the EA approach and that for some 
projects EA is essential.

In choosing an acquisition model, it may be useful to consider combinations of the different models that are available. For example, grand design projects often include some early delivery of system components. Similarly, in a large grand design project, EA may be considered for the acquisition of complex subsystems.

\section{BEST PRACTICES AND ACQUISITION REFORM INITIATIVES}

Although many other US DoD AR initiatives and best practices exist, only a few practices were identified that showed significant benefits for AR in SA. It is important that AR should also take advantage of busincss process improvements being pioneered in the private sector. The commercial sector has reorganised, restructured, and adopted revolutionary new business and management practices in order to ensure its competitive edge in the rapidly changing global marketplace. The SA DoD must adopt and adapt the lessons of the private sector, if the SANDF is to maintain its competitive edge in the rapidly changing defence environment.

\section{Cost As An Independent Variable.}

According to the U.S. Navy Acquisition Reform Office [7], Cost as an Independent Variable (CAIV) is an acquisition strategy focusing on cost-performance trade-offs in setting program goals. It entails setting aggressive but realistic cost objectives when defining operational requirements and acquiring defence systems, and managing achievement of these objectives. This strategy ensures that cost objectives balance mission needs with available and projected resources, taking into account the state of requisite technologies. CAIV does not mean trading cost, performance, and schedule equally. CAIV means picking the right affordable cost objective, and sticking to it. Key CAIV principles and practices to use for SA defence acquisition are:

- Requirements should be stated in terms of capabilities and may be exchanged, substituted, or adjusted for the sake of another.

- Required capabilities should be established at the system level and not at lower levels.

- Realistic cost objectives, that are consistent with requirements and projected fiscal resources, should be clearly defined as early as possible.

- The cost objectives must be updated for each phase of the acquisition program.

- Key trade-off areas should be identified in the Statement of Work (SOW) and specifications.

- Early and continuous customer/user participation in setting program goals throughout the program.

- Provisions for contractor participation in Integrated Product Teams (IPT) to facilitate tradeoffs during all program phases.

- Robust contractor incentives for achieving cost objectives during all program phases.

Due to budget constraints, cost is already treated as an independent variable in SA defence acquisition. Budget uncertainties, however, makes it difficult to define cost objectives that balance operational requirements with available resources and technologies.

CAIV could be a very useful technique for program management at all levels in SA defence acquisition. It is a very valuable tool for the analysis of alternatives. High-level cost 
objectives should be communicated continuously to the Armscor project managers and SANDF project officers. CAIV should be tailored to the specific circumstances of individual programs

\section{Continuous Acquisition and Life-cycle Support.}

According to the U.S. Navy Acquisition Reform Office [7], Continuous Acquisition and LifeCycle Support (CALS) is a strategy to accelerate the pace at which high quality information flows within the DoD and between the DoD and its business partners, simultaneously reducing information management overhead costs. The US DoD's overarching goal in CALS is to develop a seamless defence enterprise in which the knowledge products of the acquisition process are immediately and rapidly accessible to all users while maintaining near immediate currency and quality of information. Application of the best technologies, processes, and standards for the development, management, exchange, and use of business and technical information among and within governmental and industrial enterprises will generate an Integrated Data Environment (IDE).

An IDE and the implementing processes should be provided for the people who design, acquire, use and support weapon systems. This gives them the technical and management information needed to field, operate and sustain affordable, effective weapon systems. Ready access to accurate acquisition and logistics information improves weapon systems life cycle management enabling mission performance at lower cost.

Numerous efforts were made in the past by the SA defence family to establish a life-cycle support environment. The lack of clearly defined teams, processes, standards and information management systems made these efforts unsuccessful and costly. Electronic information flows within and between the SA DoD, Armscor and contractors needs to be improved with easy access. The US Defence Acquisition Deskbook [6] is a good example of a method for communicating processes and changes within the DoD. An IDE is however essential for AR in $\mathrm{SA}$ and needs serious consideration.

\section{Integrated Product and Process Development.}

According to the US Secretary of Defence [8], Integrated Product and Process Development (IPPD) is a management process that integrates all activities from product concept through production to field support, using a multi-functional team, to simultaneously optimise the product and its manufacturing and support processes to meet cost and performance objectives. The key elements of IPPD are:

- Customer focus.

- Concurrent development of products and processes.

- Early and continuous life cycle planning.

- Flexibility for optimisation.

- Unique approaches.

- Encourage robust design and improved process capability.

- Event-driven scheduling.

- Multidisciplinary teamwork.

- Empowerment. 
- Seamless management tools.

- Proactive identification and management of risk.

This is a key management process for effective defence acquisition in SA. IPPD depends on the product and process, and there is therefore no single solution or implementation strategy. The IPPD process in SA should however start with changes to the decision-making process, incorporating more on the functional expertise of integrated product teams. Open channels should exist to bring downstream issues to bear earlier.

\section{Integrated Product Teams.}

According to the US Secretary of Defence [8], Integrated Product Teams (IPT) is a multidisciplinary teamwork approach to implement IPPD and enable making the right decisions at the right time. IPT's are composed of representatives from all appropriate functional disciplines working together with a team leader to build successful and balanced programs, identify and resolve issues, and make sound and timely decisions. The purpose of IPT's is to make team decisions based on timely input from the entire team including customers and suppliers.

The US DoD has three different levels of IPT's. The Overarching IPT (OIPT) is at the highest level while the Program IPT operates at the program level. The Working level IPT includes officers from the Program Office and staff represented at the OIPT level. The focus and responsibilities of the three types differ.

The US IPT's are very similar to the project teams being used in SA defence acquisition. The SA project teams function only on the program level and often experience difficulties in decision-making, guidance, program status and budgets. These project teams should however be restructured and redefined in terms of authority, focus, responsibilities, members and interfaces.

Some misconceptions do exist on IPT's and the new draft policies in Armscor calls it 'Integrated Project Teams". It is however important to have IPT's with qualified and empowered team members that will focus on a certain field of expertise for decision-making. These IPT's can be used for drawing up Requests for Proposals (RFP's) or to solve specific technical problems and should exist at all levels.

The IPT concept is important for other AR initiatives such as IPPD, but should be streamlined for the SA acquisition process due to the limited acquisition workforce. Program managers should indicate the different IPT's that are needed and chair all the first level IPT's.

\section{Total Ownership Cost, CAIV and Target Cost.}

According to the US Office of the Secretary of Defense [4], Total Ownership Cost (TOC) for defence systems is often confused with Life Cycle Cost (LCC) and Operating and Support (O\&S) cost. TOC is a broader concept than LCC and O\&S cost and includes not only acquisition program direct costs, but also indirect and hidden costs attributable to the acquisition program (i.e., costs that would not occur if the program did not exist). Indirect cost would include, for example, the infrastructure that plans, manages and executes a program 
over its full life and common support items and systems.

CAIV is a process to reduce costs while TOC is a domain - a set of costs to be reduced. Reduction of TOC (R-TOC) is a program that consists of a set of processes that seeks to change:

- What is acquired (usually addressed by CAIV).

- How to acquire or operate a system (addressed in a number of ways), in order to reduce cost.

The three main objectives with the R-TOC programs are:

- To control cost (Capture and arrest cost growth).

- To reduce cost (Reduce cost and capture savings).

- Invest to modernise.

Although the same objectives exist in the $\mathrm{SA}$ DoD, no R-TOC programs have been initiated to date. This is an area where formal AR programs can show tremendous results. The challenges that are faced are the lack of TOC databases, the difficulty of capturing all TOC and the fact that TOC is confused with LCC cost and O\&S cost. Benefits of AR in the target cost demain could be to:

- Increase overall profitability.

- Reduce manufacturing costs.

- Reduce the costs of new products before manufacturing.

- Meet or exceed customer expectations.

- Reduce the cost of purchased material.

- Result in customer valued product features and functions.

- Develop a more profitable product mix.

- Decrease the number of design changes.

- Reduce time required for new product introduction.

\section{Single Process Initiative}

According to the U.S. Navy Acquisition Reform Office [7], Single Process Initiative (SPI) (also referred to as "common process initiative" or "block change process') is an initiative to consolidate or eliminate multiple management and manufacturing requirements across defence contracts on a facility-wide basis. Many methods of performing the same process are often employed to satisfy different contracts/customers. Given the fact that defence contractors may on average employ 250 or more discrete processes, any multiplication of alternate methods rapidly introduces technical and cost inefficiencies.

SPI addresses this problem by allowing contractors to propose use of their most efficient business and manufacturing practices in lieu of Government imposed standards. SPI is a streamlining initiative that can be used in SA to accomplish AR goals of cost, schedule and performance improvement by eliminating unnecessary overheads and reducing inefficiency. The SPI proposal and approval process, however, relies upon integrated product teaming and 
the reduction of military specifications and standards. SPI can reduce incidence of false starts and re-work and will encourage contractors in SA to work on defence projects and will reduce development and production costs.

\section{Contract Data Requirements List}

According to the U.S. Navy Acquisition Reform Office [7], the Contract Data Requirements List (CDRL) defines the data that is to be delivered by the contractor. This data may be in hardcopy, electronic format, electronic mail, or any other form specified. The specific form of delivery must be specified in the SOW. The AR principle in this case is online electronic media use and was discussed under CALS.

The SA DoD should require contractors to deliver data items electronically, rather than in hard copy. This practice will play an important role in AR in SA because the configuration control, handling and storage of hardcopies are becoming increasingly problematic. Projects have already been initiated by Armscor to get all existing data into electronic format. CDRL should however be implemented as soon as possible to prevent rework and to ensure that contractors deliver data electronically.

\section{Commercial Practices, Products, Processes}

Commercial off the Shelf (COTS) and Non-Developmental Items (NDI) are commercially available items that are customarily used for non-government purposes. COTS and NDI can reduce cycle times, review processes and support. These items are often better and cheaper products with better support. There are however the risks of extra test and evaluation, weaker performance and extra interfaces. Practices that AR in SA can utilise are:

- Solicitations that encourage the use of COTS and/or NDI wholly or in part.

- Streamlined configuration management requirements where the government doesn't own the design.

- Requests for offerors to provide existing test data with their proposals for possible fulfilment of test and evaluation requirements.

- Transportability requirements.

- Requests for contractors to show that COTS and/or INDI will be capable of meeting the reliability and maintainability requirements.

\section{Integrated Logistic Support}

According to the US Office of the Secretary of Defence [4], Integrated Logistic Support (ILS) is the process of acquiring the necessary system support package to provide the user with operational support at the lowest possible cost for the system when delivered. AR initiatives should encourage the development of innovative strategies for logistic support to newly delivered equipment with emphasis on affordability and total cost of ownership. More emphasis should be placed on the cost of ILS as a source selection factor since operation and maintenance/support costs represent the major part of total system life cycle costs.

As the major portion of the total system life-cycle cost is in operations and support of the equipment, these functions must be closely monitored from program conception through 
disposal. It is the Armscor program manager's responsibility to buy cost effective support to satisfy the user requirements. The operational scenario and the readiness objectives shall form the basis for this support. The total life cycle cost, including logistic support and human systems integration costs, must be demonstrated as representing the lowest cost of ownership to the user.

Logistic support implications must be fully considered to assure that support will be provided in an effective and efficient manner and in full consonance with program and user requirements. Factors such as cost of ownership, maintenance concept, standardisation and supportability, should be considered by the project team during procurement of the system's ILS.

\section{Open Systems}

According to the US Defense Acquisition University [11], an Open System (OS) is a system that has sufficiently open specifications for interfaces, services, and supporting formats to enable standardised components to be utilised across a wide range of systems with minimal changes. These components should be able to inter-operate with other components in local and remote systems, and to interact with users in a way that facilitates portability.

Improved interfaces and interoperability provides opportunity for superior performance, accelerated delivery, and more affordable systems. OS is an "enabler" for a number of AR initiatives such as CAIV, performance specifications, use of commercial items, and configuration management.

Market research is critical in the OS approach in order to determine availability of modular components that may be capable of meeting government interface/interoperability requirements. The OS approach must continuously be identified, detailed, and refined throughout the entire life cycle of the system. OS architectures may be particularly appropriate for fast changing technology, high cost items, or high usage and replacement items in the SA defence environment.

\section{Past Performance Information}

According to the U.S. Navy Acquisition Reform Office [7], Past Performance Information (PPI) is relevant data regarding a contractor's actions under previously awarded contracts. The AR principle is to move source selections into increasingly greater use of "best value" procedures, in which considerations of non-cost factors (such as technical, management and PPI) might justify award to other than the apparent low-cost offeror. It is closely related to other AR initiatives, such as risk management, affordability and best value.

PPI should demonstrate the offeror's successful corrective actions and recovery from cost/schedule/performance problems. Contract performance is rarely without some unanticipated disruption or problem in conforming to all plans and requirements. Therefore a history of successful corrective actions should be a critical issue for source selection. The exact weight shall be tailored to the unique requirements of each RFP.

Although PPI is used for source selection in the US, the lack of local competition, the limited 
number of contracts and the small defence budget makes the use of such non-costing factors less feasible in SA. Successful past performance may be attributed to the performance of key personnel. This may be a critical predictor of future performance in some acquisitions and a requirement for PPI on key personnel could exist.

PPI could be linked with the accreditation program in Armscor and must be updated with electronic media information from both the Armscor program manager and contractors.

\section{Performance Measurement with Earned Value Management}

Performance measurement is an element of the earned value management process. Earned value is the value of the accomplished work against the planned budget. The earned value management process relies on the implementation of Earned Value Management Systems (EVMS) criteria, and the integration of cost, schedule and technical performance. These EVMS criteria can be used to ensure that a contractor's cost/schedule management system is able to provide accurate data to monitor execution of the program.

When invoking the EVMS criteria requirements in a contract, the program manager should first asses the technical risks on the contract and determine the Work Breakdown Structure (WBS) level at which performance visibility is necessary. It is equally important to determine the level of cost/ schedule reporting to the government. The program manager should request all cost/schedule data using Electronic Data Interchange (EDI) standards.

Performance measurement is an important issue that should be addressed in Armscor's management system and also in solicitations to the contractors. Cash-flow reviews are inadequate and not accurate due to poor synchronisation between budget approvals and review schedules. EVMS should be encouraged and implemented at main contractors.

\section{Requirement Management}

Requirement Management is the practices and procedures for a disciplined approach to identify, understand, translate, and process requirements from the user and to ensure that these requirements are being satisfied.

AR efforts in SA should include:

- Clearly defined performance-based statements of work.

- Clearly defined performance specifications.

- Detailed, comprehensive and very descriptive RFP's.

- Performance measurement.

IPT's may play a key role in requirement management. This is one area that needs intensive efforts from the acquisition workforce in SA.

\section{Performance-based Statement of Work}

According to the US Defense Acquisition University [10], a performance-based Statement of Work (SOW) is a description of the tasks to be performed by the contractor in terms of 
required outcomes or results. A non-performance-based SOW details how the contractor is expected to accomplish the work.

With a performance-based SOW, accountability for the final outcome is more clearly drawn; the contractor remains responsible and accountable for achieving the required resuits based upon their own technical and management approach and intemal processes which have not been prescribed by the Government. Thus, the offeror is given greater flexibility in his proposal but absorbs a commensurably greater share of the risk for contract performance. The following principles should be applied for performance-based SOW:

- Tasks should be stated in such a way that the contractor knows what is required.

- Correctly cited references.

- Formal, measurable performance standards.

- Correctly cited, tailored, and applied military specifications and standards, if authorised.

- Task completion criteria.

- Avoid unnecessary "how-to" requirements that preclude "best value" source selection.

- Avoid over-specification of requirements.

Performance-based SOW is most applicable for AR in SA. The lack of clearly defined SOW's to contractors is a major problem in defence acquisition. Non-performance-based SOW's are often prepared by contractors, due to the lack of skilled program managers and other acquisition workforce members. Actions should be taken to ensure that formal and comprehensive User Requirements Specifications (URS) are given to the Armscor program managers to enable the project team to draw up a performance-based SOW. The IPT's should play an important role to achieve this very important AR objective.

\section{Performance Specifications}

According to the U.S. Navy Acquisition Reform Office [7], a performance specification defines the functional requirements for the item, the environment in which it must operate, and the interface and interchangability requirements. AR is striving to reduce Government risk by using performance based specifications and standards which make the contractor responsible for providing the items or services requested, assume the risk for meeting performance requirements, and seek innovations to efficiently and effectively achieve performance objectives. Good practices in this area are:

- If the requirement imposes a design solution, it should do it conditionally.

- Requirements must be derived from a higher-level requirement.

- The performance specifications should state "what we need" and "how we validate".

- The performance required must be stated in such a way that it can be measured, verified and evaluated.

\section{Military Specifications and Standards}

Traditionally Defence Departments have relied on the use of military specifications and invoked a standard system of quality assurance methods, testing methods and product quality 
assurance methods. This did not allow or encourage contractors to be innovative or take advantage of alternative design, test and manufacturing techniques. Consequently the state was not able to take advantage of potential cost savings. Specifications also contained a multitude of detailed design requirements to assure the design and manufacture of quality products. With the advent of performance based specifications the majority of these requirements have either been eliminated or are restated in performance terms.

Military specifications and standards should therefore be clearly identified as either "mandatory" of "for guidance only". Contractors should be encouraged to submit alternative solutions to the use of military specifications and standards.

\section{Electronic Source Selection}

According to the US Office of the Secretary of Defence [4], Electronic Source Selection (ESS) is the integration of communication technology, data base applications, and information management systems to reduce risk and increase the productivity and efficiency of source selection evaluations. ESS uses standard office software applications and hardware to produce a "paperless environment" for source selections and to streamline RFP preparation. ESS has been successfully used in major US DoD programs.

Many AR principles are promoted through the use of ESS, with particular emphasis on streamlining, best value, and electronic commerce. The productivity of the ESS tool to reduce risk, cost and time associated with evaluation of proposals is a big advantage. The electronic control of sensitive information and rapid access to information by decision-makers reduces risk.

It is however essential to perform a return on investment analysis to ensure that the cost of running an ESS process is cost effective, particularly if contractor services are being used for ESS support. Security requirements should be properly documented.

ESS is a very applicable best practice for AR in SA and it is recommended that AR actions in this area should be initiated. Certain phases or actions (i.e. RFP's) in the acquisition process can already make use of electronic media.

\section{Simplified Acquisition Procedures}

Simplified Acquisition Procedures (SAP) are streamlined techniques and guiding principles designed to reduce the administrative burden of awarding the lower Rand value procurements that account for the vast majority of SA DoD acquisition. They allow informal quoting and competition procedures, encourage accepting oral quotations instead of written quotations, prefer comparing quoted prices instead of conducting negotiations, and provide streamlined clauses to support the award document.

SAP provides relief from the administrative costs, burdensome rules and time frames otherwise required in the acquisition process. Application of electronic commerce will further facilitate this streamlined acquisition process by ensuring better access by industry to government contracting opportunities while minimising procurement lead time. Collectively, these techniques align SAP much more closely with standard commercial practices and their associated benefits. 
Methods that are used by the US DoD for making use of simplified acquisition procedures, includes the Purchase Card, Blanket Purchase Agreements, Purpose Orders and using the SF1449 in conjunction with the purchase of commercial items.

Armscor uses different levels of authorisation to simplify acquisition procedures, but this does not simplify the procedure at all: SAP is a necessary AR effort to be taken to reduce time and cost.

\section{Streamlining}

Streamlining is the process of taking appropriate actions to reduce the time required to procure the acquisition, reduce the cost of the acquisition and improve the quality of the acquisition through more effective, concise communications. The US DoD streamlining efforts are implemented throughout their research, development, test and evaluation infrastructures, acquisition processes, acquisition organisation and logistics.

Streamlining is a central technique for reducing costs, primarily through elimination of unnecessary redundant and burdensome administrative elements. It is therefore essential to appoint AR champions, AR teams and AR programs to determine and achieve streamlining objectives in SA.

\section{AN ACQUISITION REFORM MODEL}

The SA DoD needs a process to identify and implement the necessary AR projects or actions. This process should be a guideline for planning, organising, co-ordinating and controlling all AR activities. A very useful AR concept called "The Acquisition and Sustainment Reinvention Process" was initiated by the US Air Force in May 1998 [11].

This concept, using a process oriented approach, leverages ideas for improvement in acquisition practices, processes, and procedures directly from the workforce and industry, and is designed to make acquisition better, faster, and cheaper. At its core, the concept builds upon the substantial reforms already implemented or currently in progress, and incorporates continuous communication and feedback across four key phases:

Phase 1 - Identify. The first phase focuses on members of the acquisition workforce, industry or institutes, who are actively exploring and submitting ideas for consideration. These thinkers and innovators are continuously seeking out ineffective or ailing process elements and developing new ideas, innovations, and fixes for outdated ways of doing business. They are also the acquisition and management professionals who possess the hands-on knowledge and insights into ways in which the work can be done smarter, better, faster, and cheaper.

Phase 2 - Study and Develop. The second phase includes analysing existing activities to better integrate related efforts and better understand the existing body of knowledge and initiatives. This phase also includes establishing AR teams to examine particular opportunities that are identified for study. Each team will build a change package for achieving aggressive performance goals through design of processes, realignment of workforce rewards, incentives, education; and proactive management of the change process itself. 
Phase 3 - Test. In the third phase each innovation package will be tested and validated in a real-world environment to assess the reinvention package design, design stability, further refinements needed, and management acceptance. A detailed implementation plan and a communication plan for introduction to the acquisition workforce will also be developed. Following successful development of the plans, the entire package must be presented to management.

Phase 4 - Deploy. In the final phase of the acquisition and sustainment reinvention process the innovation packages will be implemented across the acquisition workforce to deliver required capabilities to the Defence Force. A key element of this phase is the education and training of the acquisition workforce to provide them with the tools, knowledge, skills, and understanding necessary to implement change, where needed, quickly and effectively.

\section{CONCLUSION}

Defence acquisition in the US DoD is on a different level than in the SA DoD. The US acquisition workforce is large enough to specialise in every field or activity and they have the necessary structures, processes, funds, skills, and experience to do so. The total acquisition process and also the AR process in the US DoD is still expensive, labour intensive and time consuming.

The acquisition- workforce, organisation, process, and structures in SA differs much from that in the US DoD. AR should be tailored to fit the scale of acquisition and situation in SA. However, much can be learned from the US DoD experience, initiatives, practices and achievements and it can be used as a guideline to restructure the SA acquisition workforce and to get AR going. The following AR actions are proposed:

- Define different types of acquisition projects and their applicable acquisition methods and identify AR champions who will drive AR projects.

- High level and aggressive cost objectives should be determine and communicated continuously to the Armscor project managers and SANDF project officers.

- Improve and establish effective electronic information flows within and between the SA DoD, Armscor and contractors.

- Pilot AR programs should be initiated that will focus on modernisation of equipment and to reduce Total Ownership Cost.

- CDRL should be implemented to prevent rework and to ensure that contractors deliver data electronically. This should enhance configuration control efforts.

- AR projects are necessary so that Armscor program managers can spend more time on the technical, cost and time issues of projects.

- Earned value management systems should be encouraged and implemented at certain main contractors.

- Performance measurement techniques should be implemented.

- Simplified Acquisition Procedures (SAP) should be implemented, to reduce time and cost.

- The structuring and implementation of IPT's.

- Restructure and implement a requirement management system within Armscor and the SA DoD to enable properly constructed RFP's, SOW's and performance specifications.

- The maintenance and use of testing-, measuring-, evaluating-, simulating- and 
modelling laboratories and facilities must be shared between the different SANDF Arms of Service.

The Acquisition and Sustainment Reinvention Process (ASRP) from the US DoD is a very useful concept that can be used to implement AR locally. AR in SA can use this as a basis to identify, design, test and implement AR activities. The concept is simple, yet practical and easy to implement. The concept does however need support and co-operation at all levels and AR champions to drive it.

Although the importance of $\mathrm{AR}$ are realised, more co-operative and co-ordinating acquisition efforts are needed by Armscor, the Defence Secretariat and the SANDF to sell AR and to achieve the culture change and paradigm shifts needed within the acquisition workforce. Implementing $\mathrm{AR}$ in $\mathrm{SA}$ will require a coordinated systematic process of identifying, designing, testing and implementing AR that will involve all the parties involved, including the defence industry.

\section{REFERENCES}

[1] SA Department of Defence, 1996, "Defence in a democracy, SA White Paper on Defence", SA Department of Defence.

[2] US Department of Defense, 1996, "Defense Acquisition", Directive 5000.1, US Department of Defense ,Washington, DC.

[3] Office of the Deputy Under Secretary of Defense for Acquisition Reform, http://www.acq.osd.mil/ar/

[4] US Office of the Secretary of Defense, 1999, "Defense Acquisition Deskbook", CD version 2.7, US Office of the Secretary of Defense.

[5] Armscor, 1994, "General Policy for the Management of Category I Materiel Acquisition Process", Policy document VB 1000, Armscor.

[6] Offices of the Under Secretary of Defense, Defense Acquisition Deskbook, http://www.deskbook.osd.mil/

[7] US Navy Acquisition Reform Office, "Turbo Streamliner", http:/www.acqref.navy.mil/turbo/

[8] Secretary of Defense Perry, W. J., 1995, "Use of Integrated Product and Process Development and Integrated Product Teams in DoD Acquisition", Office of the Secretary of Defense, Washington, DC.

[9] US Department of Defense, 1996, "Mandatory Procedures for Major Defense Acquisition Programs (MDAPs) and Major Automated Information System (MAIS) Acquisition Programs", Directive 5000.2-R, US Department of Defense, Washington, DC.

[10] Defense Acquisition University, http://www.acq.osd.mil/dau/arcc/

[11] Office of the Assistant Secretary of the Air Force (Acquisition Office), "Air Force Acquisition Reform", http://www.safaq.hq.af.mil/acq_ ref/ 